\title{
Recurrent Urinary Tract Infections Risk Factors in Patients with Primary Vesicoureteral Reflux
}

\author{
SARDAR KHAN ${ }^{1}$, SAJJAD HUSSAIN ${ }^{2}$, ZAHIR SAID ${ }^{3}$, IHSAN UL HAQ ${ }^{4}$, HABIB U REHMAN ${ }^{5}$, AYAZ AHMED 6 \\ ${ }^{1}$ Associate Professor, Department of Paediatric, Saidu Medical College Swat \\ ${ }^{2}$ Assistant Professor, Department of Paediatric, Saidu Medical College Swat \\ ${ }^{3}$ Senior Registrar, Department of Paediatric, Saidu Medical College Swat \\ ${ }^{4}$ ProfessorDepartment of Paediatric, Saidu Medical College Swat \\ ${ }^{5,6}$ Senior Registrar, Department of Paediatric, Saidu Medical College Swat \\ Corresponding author: Dr. Sardar Khan, Email: sardarkhan629@yahoo.com, Cell No.+923330259054
}

\begin{abstract}
Background: Knowing the risk of recurrence of urinary tract infection (UTI) in vesicoureteral reflux (VUR) can assist clinicians to sort therapeutic decisions. The current study's aim was to assess the association of UTI in VUR. Additionally, UTI recurrence might be predicted by the risk score.

Materials and Methods: This case-control study was carried out on 123 children at department of Paediatric, Saidu Group of Teaching Hospitals, Swat for the duration of one year from $1^{\text {st }}$ July 2020 to $30^{\text {th }}$ June 2021. Out of 123 children, the group-I had 57 children with documented previous UTIs history while group-II had 66 children with no previous UTIs and was referred to as a control group. All the patients were VUR diagnosed and were thoroughly followed up at a Renal Unit of single tertiary. UTI recurrence was referred to more than one follow-up episode. A regression model was used for independent variables identification regarding UTI recurrence. . A questionnaire on bowel habits was provided to the parents. The abdominal plain film was evaluated by the observer and recorded on the documented scoring system. The constipation history was compared with the radiological and symptomatic scores. Organism single species with $>105 / \mathrm{ml}$ count in a single midstream catch of urine sample was reflected as UTI evidence.

Result: Out of 123 children, $88(71.5 \%)$ were females while $35(28.5 \%)$ were male. A total of 123 children had been investigated for UTI complaints. After the multivariable analysis adjustment, five recurrent UTIs predictor variables were the clinical presentation of UTI, female gender, reflux several grades, age less than 6 months, and syndrome dysfunction elimination. The UTIs recurrence risk factors were classified as high, medium, and low with prevalence $52(42 \%), 41(34 \%)$, and $30(24 \%)$ respectively. The prevalence of UTIs rate per person-month was $10.9(95 \% \mathrm{Cl}, 9.8,12.7), 8.2(95 \% \mathrm{Cl}, 6.7,9.1)$ for medium, and $5.2(95 \% \mathrm{Cl}, 3.3,5.5)$ for the low-risk group.

Conclusion: The formulation of therapeutic strategies can be done based on prediction model for UTIs recurrence besides early detection of morbidity long-term risk for the patients.

Keywords: Vesicoureteral reflux, Urinary tract infection, Dysfunctional voiding, Constipation
\end{abstract}

\section{INTRODUCTION}

Hypertension, renal scarring, and later-stage renal disease of children are prompts by the primary vesicoureteral reflux (VUR) and urinary tract infection (UTI) combination [13].Subsequently, renal failure or injuries prevention of children from VUR further infection could be managed by current strategy and treatment [4]. Surgical correction and long-term prophylaxis (antimicrobial) have been the two main motilities for treatment. VUUR's natural tendency to improve medical management and time is relatively covered by the renal damage duration caused by VUR [5]. The risk of UTI recurrence in individual children should be considered by clinicians with established medical management. Vesicoureteral reflux (VUR) chances increased in children of age below 5years. VUR chances increased with associated constipation. Bowel habits should be inquired for UTIs infection evaluation. Constipation relief can result in disappear UTIs recurrence [6]. Hypertension risk and renal failure increased as renal scarring comes from severe bilateral caused by subclinical infection of UTIs long-term consequences. Therefore, serious consideration must be taken even for a single UTI. Asymptomatic bacteria is clinically silent among some children. Spontaneous remission might appear in children within few months and better to be left untreated. Asymptomatic bacterial reflux was found in $11 \%$ cases [7].
The proportion of VUR and renal scarring was found $35 \%$ and $10-25 \%$ cases upon screening of asymptomatic schoolaged children. Undiagnosed infection and UTIs symptomatic prior history were found among many of these children [8]. The distinction between subclinical infection and asymptomatic was difficult to be found in the laboratory or clinically.

Constipation is undiagnosed and poorly treated pediatric problem. People especially children's guardians should be aware of constipation complications and effects. Larger fecal reservoirs have been recorded in rectal manometry and examination in children of repeated UTIs. As the micturition increases among children, renal tract dilatation and residue bladder significantly increased constipation and improved with treatment [9]. Urinary tract infection and vesicoureteral reflux caused by detrusor stretch receptors simulation by inhibited bladder and emptying loaded impair rectum bladder due to mechanical load in chronic constipation [10].Number of researchers described the correlation between UTIs and severe constipation among children and found that loaded rectum due to mechanical effect and sigmoid colon distortion leads to urethra elongation and bladder displacement thus causing emptying impaired bladder and hydronephrosis [11]. One study showed emptying impaired bladder association with constipation [12]. Another study reported a 
large rectal reservoir found by manometry and rectal examination of UTIs history in children prior to constipation [13]. The present study was carried out to analyze outcome and adolescents of children with primary VUR with aims to find the UTIs recurrence rate and risk factors for medical treatment.

\section{MATERIALS AND METHODS}

This case-control study was carried out on 123 children at department of Paediatric, Saidu Group of Teaching Hospitals, Swat for the duration of one year from $1^{\text {st }}$ July 2020 to $30^{\text {th }}$ June 2021 . Out of 123 children, the group-I had 57 children with documented previous UTIs history while group-II had 66 children with no previous UTIs and was referred to as a control group. All the patients were VUR diagnosed and were thoroughly followed up at a Renal Unit of single tertiary. UTI recurrence was referred to more than one follow-up episode. A regression model was used for independent variables identification regarding UTI recurrence. A questionnaire on bowel habits was provided to the parents. The abdominal plain film was evaluated by the observer and recorded on the documented scoring system. The constipation history was compared with the radiological and symptomatic scores. Organism single species with $>105 / \mathrm{ml}$ count in a single midstream catch of urine sample was reflected as UTI evidence. All the patients with primary VUR followed by three months duration were included in this study. Patients with neurogenic bladder, ectopic ureterocele, obstructive uropathies, and posterior urethral valves were excluded.

Conventional voiding cystourethrography was used for VUR diagnosis at the time of admission. A systematically proposed reflux grade was categorized as first voiding cystourethrography. A single dose routine of 1 to $2 \mathrm{mg} / \mathrm{kg}$ nitrofurantoin and trimethoprim was followed to maintain antibiotic prophylaxis among children. VUR correction was done with antibiotics prophylaxis failure as indicated surgical procedure for severe reflux. A systematic protocol was followed after the initial investigation. Our study prime outcomes were incidence of UTI and infections through recurrent UTI break through. The predictive variables for our study were gender, age, lower UTI, dysfunctionality syndrome (lower UTIs and constipation), renal damage, VUR grade (mild/moderate/severe), clinical presentation (fetal hydronephrosis/UTI), reflux laterality (unilateral/bilateral) and renal damage severity.

\section{RESULTS}

A total of 123 children had been investigated for UTI complaints. Out of 123 children, 88 (71.5\%) were females while $35(28.5 \%)$ were male.After the multivariable analysis adjustment, five recurrent UTIs predictor variables were the clinical presentation of UTI, female gender, reflux several grades, age less than 6 months, and syndrome dysfunction elimination. The UTIs recurrence risk factors were classified as high, medium, and low with prevalence 52 (42\%), 41 (34\%), and 30 (24\%) respectively. The prevalence of UTIs rate per person-month was $10.9(95 \%$ $\mathrm{Cl}, 9.8,12.7), 8.2(95 \% \mathrm{Cl}, 6.7,9.1)$ for medium, and 5.2 $(95 \% \mathrm{Cl}, 3.3,5.5)$ for the low-risk group.Of the total 123 patients, $88(71.5 \%)$ were females and $35(28.5 \%)$ were male as shown in Table/Figure-1.Table-2 demonstrates the baseline characteristics such as age, the clinical presentation of 123 patients.Figure-2 shows the clinical presentation of 123 patients. The grade I-II reflux was 42 (34.1\%), grade-III was 40 (32.5\%) and Grade IV-V was 41 (33.3\%). These grades of reflux such as I-II, III, and IV-V with their prevalence are shown in Table/Figure-3.

Table-1. Gender distribution of 123 Patients

\begin{tabular}{|l|l|l|}
\hline Gender & Frequency $(\mathrm{n})$ & Percentage $(\%)$ \\
\hline Male & 35 & 28.5 \\
\hline Females & 88 & 71.5 \\
\hline Total & 123 & 100 \\
\hline
\end{tabular}

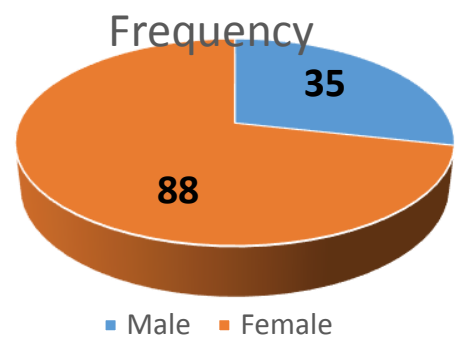

Figure-1 Gender distribution

Table-2. Baseline characteristics of 123 patients

\begin{tabular}{|l|l|}
\hline Parameters & Value N (\%) \\
\hline Diagnosis Age (Months) & \\
\hline Median & 22.7 \\
\hline Interquartile range & $9.9-43.5$ \\
\hline Mean & 31.3 \\
\hline SD & 11.4 \\
\hline Clinical presentation & \\
\hline Urinary infection & $110(89.5)$ \\
\hline Fetal hydronephrosis & $11(8.9)$ \\
\hline Familial history & $2(1.6)$ \\
\hline
\end{tabular}

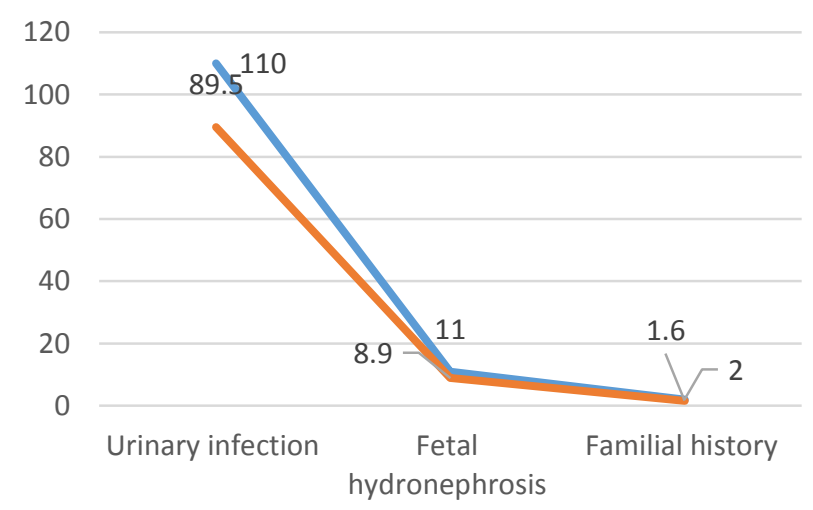

Frequency Percentage

Figure-2. Clinical presentations of 123 patients

Table-3. Reflux grades for 123 patients

\begin{tabular}{|l|l|l|}
\hline Grade of Reflux & Frequency $(\mathrm{n})$ & Percentage $(\%)$ \\
\hline I-II & 42 & 34.2 \\
\hline III & 40 & $32.5 \%$ \\
\hline IV-V & 41 & 33.3 \\
\hline Total & 123 & 100 \\
\hline
\end{tabular}




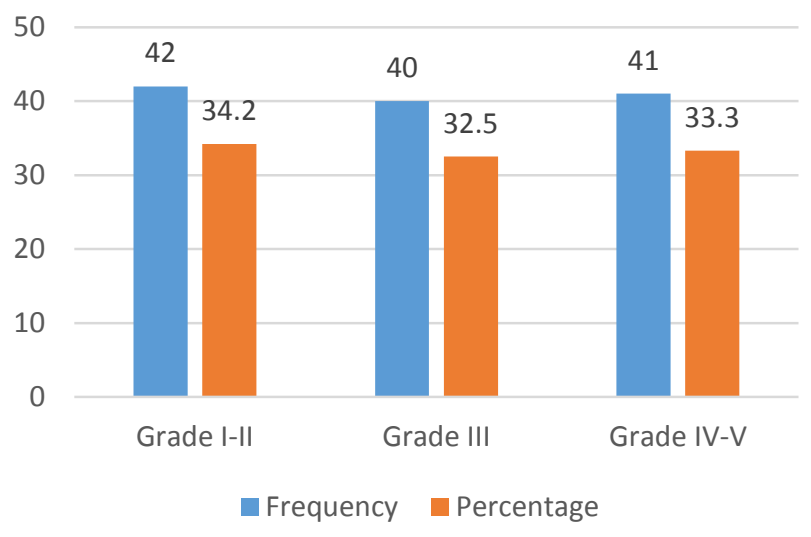

Higher incidence of UTIs was significantly associated with variables such as female gender, age, DES, constipation. While VUR severe reflux grade (IV-V) was associated with UTIs higher incidence rate as shown in Table-4. Multivariable analysis involvesnine different variables gender, LUTD, DES, clinical presentation, age, refluxgrade, renal damage, and reflux laterality. Out of these five independent predictors for UTI recurrence were age, DES, female gender, severe grade, andclinical presentation as shown in Table 4.

Figure-3: Grades of Reflux among 123 patients

Table-4 the incidence rate of UTIs with baseline characteristics.

\begin{tabular}{|l|l|l|l|}
\hline Features & Incidence rate of UTIs & Ratio $(\mathrm{Cl}, 95 \%)$ & P-value \\
\hline Presentation & & $1.35(0.89,2.0)$ & 0.12 \\
\hline Fetal/other & $(23 / 123)$ & $6.4(3.9,9.2)$ & \\
\hline UTI & $(68 / 123)$ & $8.5(7.7,9.5)$ & \\
\hline Lower urinary tract dysfunction & & $1.6(1.3,2.0)$ & $<0.001$ \\
\hline Present & $34 / 123$ & $12.6(10.6-15)$ & \\
\hline Absent & $89 / 123$ & $7.3(6.5-8.2)$ & $<0.001$ \\
\hline Constipation & & $1.5(1.2-1.7)$ & \\
\hline Present & $47 / 123$ & & $<0.001$ \\
\hline Absent & $78 / 123$ & & \\
\hline Dysfunctional elimination syndrome & & $1.5(1.2-1.7)$ & \\
\hline Present & $53 / 123$ & & $<0.001$ \\
\hline Absent & $70 / 123$ & & \\
\hline Age $<6$ mo & & $1.48(1.2-1.7)$ & \\
\hline Present & $31 / 123$ & & \\
\hline Absent & $93 / 123$ & & \\
\hline
\end{tabular}

\section{DISCUSSION}

The current study investigated the UTI recurrence incidence with primary VUR and possible predictive variables in the pediatric population. Our investigation findings reported the UTI incidence rate decrease after reflux treatment at 24 months sharp changes. Five significant contributors were identified as risk factors associated with the UTIs recurrence frequency using multivariable analysis. Effective stratification of pediatric VUR was classified as low, medium, and high risks after medical treatment. The prevalence of UTI recurrence is higher among children despite careful follow-up and early management. In our study, about $37.5 \%$ of patients had UTI but uncommon recurrence. More than one episode of follow-up was presented among $16 \%$ of children. All these findings matched interestingly with another study [14-16]. In multivariable analysis, recurrent UTIs had five major predictive factors such as age, female gender, clinical presentation, DES, and reflux severity. Our study findings matched another study [17] conducted on 290 children with age <5years, symptomatic UTI (27\%), recurrent UTI risk factors at age $<6$ months baseline and VUR grade. Gender distribution in our study was found insignificance but female's prevalence was higher among 123 children in our study. Another study found $36 \%$ UTI recurrence among 226 children, without any difference between patients. The presence and absence of renal scarring were associated with reflux grade. However, severe grades of reflux between III-V were stratified with no significant differences. Dysfunction elimination of the patients was 12 versus 7.6 per 1000 months in asymptomatic children [18-19]. Children with DES had a double risk for UTI recurrence compared to those without dysfunctional voiding and constipation [20].

Another study found primary VUR among 143 patients, out of which 70 children were breakthrough UTI, DES with 54(77\%) [21]. One study reported severe influx in infants showed $47 \%$ of children breakthrough but reached $69 \%$ of bladder dysfunction [22]. Another recent study showed VUR successful treatment with hyaluronic acids 2 months predictive factors including febrile higher risk and dysfunctional elimination [23]. VUR of effective children were stratified at three different degrees of UTI recurrence risk factors. A simple method of easily collected routine variables for clinical evaluation and imaging testing. Further studies need to be carried out for validating large and prospective series. The UTI recurrence incidence was decreased with intervention amenable factors in clinical implication of our analysis. Reflux severity, gender, and patients inherited conditions for recurrent UTIs were the most associated factors in our study. For managing UTIs, a target candidate remains only DES. UTI recurrence can be reduced by constipation and bladder dysfunction management. Comprehensive ultrasonography and clinical history details of the UTIs were mostly identified as DES. 
Still, for infants, optimum management identificationis troublesome [24].

\section{CONCLUSION}

The formulation of therapeutic strategies can be done based on prediction model for UTIs recurrence besides earlydetection of morbidity long-term risk for the patients.

\section{REFERENCES}

1. Buettcher M, Trueck J, Niederer-Loher A, Heininger U, Agyeman P, Asner S, Berger C, Bielicki J, Kahlert C, Kottanattu L, Meyer Sauteur PM, Paioni P, Posfay-Barbe K, Relly C, Ritz N, Zimmermann P, Zucol F, Gobet R, Shavit S, Rudin C, Laube G, von Vigier R, Neuhaus TJ (2020) Swiss consensus recommendations on urinary tract infections in children. Eur $\mathrm{J}$ Pediatr. https://doi.org/ 10.1007/s00431-020-03714-4

2. Khan A, Jhaveri R, Seed PC, Arshad M (2019) Update on associated risk factors, diagnosis, and management of recurrent urinary tract infections in children. J Pediatric Infect Dis Soc 8:152-159. https:// doi.org/10.1093/jpids/piy065

3. Mina-Riascos SH, Fernández N, García-Perdomo HA (2021) Effectiveness and risks of endoscopic management compared to vesicoureteral reimplantation in patients with high-grade vesicoureteral reflux: systematic review and network metaanalysis. Eur J Pediatr. https://doi.org/10.1007/s00431-02103948-w

4. Skoog SJ, Peters CA, Arant BS Jr, Copp HL, Elder JS, Hudson RG, Khoury AE, Lorenzo AJ, Pohl HG, Shapiro E, Snodgrass WT, Diaz M (2010) Pediatric vesicoureteral reflux guidelines panel summary report: clinical practice guidelines for screening siblings of children with vesicoureteral reflux and neonates/infants with prenatal hydronephrosis. J Urol. 184:1145-1151. https://doi.org/10.1016/j. juro.2010.05.066

5. Peters CA, Skoog SJ, Arant BS Jr, Copp HL, Elder JS, Hudson RG, Khoury AE, Lorenzo AJ, Pohl HG, Shapiro E, Snodgrass WT, Diaz M (2010) Summary of the AUA guideline on management of primary vesicoureteral reflux in children. $J$ Urol. 184:1134-1144. https://doi.org/10.1016/j.juro.2010.05.065

6. Moriya K, Mitsui T, Kitta T, Nakamura M, Kanno Y, Kon M, Nishimura Y, Shinohara N, Nonomura K (2015) Early discontinuation of antibiotic prophylaxis in patients with persistent primary vesicoureteral reflux initially detected during infancy: outcome analysis and risk factors for febrile urinary tract infection. U Urol 193(2):637-642. https://doi.org/10.1016/j.juro.2014.08.007.

7. Hoberman A, Greenfield SP, Mattoo TK, Keren R, Mathews R, Pohl HG, Kropp BP, Skoog SJ, Nelson CP, Moxey-Mims M, Chesney RW, Carpenter MA (2014) Antimicrobial prophylaxis for children with vesicoureteral reflux. N Engl J Med 370(25):23672376. https://doi.org/10.1056/NEJMoa1401811.

8. de Bessa J, de CarvalhoMrad FC, Mendes EF, Bessa MC, Paschoalin VP, Tiraboschi RB, Sammour ZM, Gomes CM, Braga LH, Bastos Netto JM (2015) Antibiotic prophylaxis for prevention of febrile urinary tract infections in children with vesicoureteral reflux: a meta-analysis of randomized, controlled trials comparing dilated to nondilated vesicoureteral reflux. J Urol 193(5 Suppl):1772-1777. https://doi.org/10.1016/j.juro.2014.10.092

9. Lee T, Park JM (2017) Vesicoureteral reflux and continuous prophylactic antibiotics. InvestigClinUrol 58(Suppl 1):S32-S37. https://doi.org/10.4111/icu.2017.58.S1.S32

10. Stein R, Dogan HS, Hoebeke P, Kočvara R, Nijman RJ, Radmayr C, Tekgül S, Urology EAo Urology ESfP (2015) Urinary tract infections in children: EAU/ESPU guidelines. EurUrol 67(3):546-558. https://doi.org/10.1016/j.eururo.2014.11.007.
11. Loukogeorgakis SP, Burnand K, MacDonald A, Wessely K, De Caluwe' D, Rahman N, Farrugia MK (2020) Renal scarring is the most significant predictor of breakthrough febrile urinary tract infection in patients with simplex and duplex primary vesicoureteral reflux. J PediatrUrol 16(2):189.e181-189.e187. https://doi.org/10.1016/j.jpurol.2019.11.018.

12. Shaikh N, Haralam MA, Kurs-Lasky M, Hoberman A (2019) Association of renal scarring with number of febrile urinary tract infections in children. JAMA Pediatr. https://doi.org/10.1001/jamapediatrics.2019.2504.

13. Braga LH, D'Cruz J, Rickard M, Jegatheeswaran K, Lorenzo AJ (2016) The fate of primary nonrefluxingmegaureter: a prospective outcome analysis of the rate of urinary tract infections, surgical indications and time to resolution. J Urol 195:1300-1305. https://doi.org/10.1016/j.juro.2015.11.049.

14. Braga LH, Mcgrath M, Farrokhyar F, Jegatheeswaran K, Lorenzo AJ (2018) Society for Fetal Urology classification vs urinary tract dilation grading system for prognostication in prenatal hydronephrosis: a time to resolution analysis. J Urol 199:16151621. https://doi.org/10.1016/j.juro.2017.11.077.

15. Visuri S, Kivisaari R, Jahnukainen T, Taskinen S (2018) Postnatal imaging of prenatally detected hydronephrosis-when is voiding cystourethrogram necessary? PediatrNephrol 33:1751-1757. https://doi.org/10.1007/s00467-018-3938-y

16. Jackson JN, Zee RS, Martin AN, Corbett ST, Herndon CDA (2017) A practice pattern assessment of members of the Society of Pediatric Urology for evaluation and treatment of urinary tract dilation. $\quad \mathrm{J} \quad$ PediatrUrol 13:602-607. https://doi.org/10.1016/j.jpurol.2017.03.032

17. Arlen AM, Scherz HC, Filimon E, Leong T, Kirsch AJ (2015) Is routine voiding cystourethrogram necessary following double hit for primary vesicoureteral reflux? J PediatrUrol 11:40.e1-40.e5. doi:https://doi.org/10.1016/j.jpurol.2014.11.011.

18. Braga LH, Mijovic H, Farrokhyar F, Pemberton J, DeMaria J, Lorenzo AJ (2013) Antibiotic prophylaxis for urinary tract infections in antenatal hydronephrosis. Pediatrics 131:e251e261. https://doi.org/10.1542/peds.2012-1870.

19. Hoberman A, Greenfield SP, Mattoo TK, Keren R, Mathews R, Pohl HG, Kropp BP, Skoog SJ, Nelson CP, Moxey-Mims M, Chesney RW, Carpenter MA (2014) Antimicrobial prophylaxis for children with vesicoureteral reflux. N Engl J Med 370:23672376. https://doi.org/10.1056/NEJMoa1401811

20. Herz D, Merguerian P, McQuiston L (2014) Continuous antibiotic prophylaxis reduces the risk of febrile UTI in children with asymptomatic antenatal hydronephrosis with either ureteral dilation, high-grade vesicoureteral reflux, or ureterovesical junction obstruction. J PediatrUrol 10:650-654.

21. Mohammadjafri $H$, Alam A, Mohammadi S, Mousavi SA, Kosaryan A, Khademloo M, Abedi M (2013) Outcome of vesicoureteral reflux in infants: impact of prenatal diagnosis. Iran J Pediatr 23:439-444.

22. Visuri S, Jahnukainen T, Taskinen S (2016) Incidence of urinary tract infections in infants with antenatally diagnosed hydronephrosis - a retrospective single center study. J PediatrSurg https://doi.org/10.1016/j.jpedsurg.2016.11.038.

23. Zee RS, Herbst KW, Kim C, McKenna PH, Bently T, Cooper CS Herndon CD (2016) Urinary tract infections in children with prenatal hydronephrosis: a risk assessment from the Society for Fetal Urology Hydronephrosis registry. J PediatrUrol 12:261.e17. https://doi.org/10.1016/j.jpurol.2016.04.024.

24. Apolicchio J-P, Braga LH, Szymanski KM (2017) Canadian Urological Association/Pediatric Urologists of Canada guidelines on the investigation and management of antenatally detected hydronephrosis. Can UrolAssoc J 12:85-92. https://doi.org/10.5489/cuaj.5094. 